\title{
Mathematics and Culture in Micronesia: An Exploration of the Mathematical Aspects of Indigenous Practices
}

\author{
A.J. (Sandy) Dawson
}

\begin{abstract}
Aims
The aims of the discussion group are to (1) discuss the findings of the three indigenous authors (Mamangon, Moses and Velasquez) investigations thus far relative to mathematics and culture in Micronesia, (2) explore the challenges and successess achieved in using elders to uncover and validate indigenous knowledge and practices, (3) explore the pedagogical issues of how to translate the findings into materials and approaches suitable for elementary school children, and (4) consider implications for future research in other indigenous cultures. Indigenous mathematics, enthnomathematics, cultural-based mathematics
\end{abstract}

\section{Key Questions}

The discussion will allow an exchange of ideas, successes, and challenges in supporting indigenous activities, capturing the mathematics contained therein, and preserving those activities and the mathematics for future generations. The key questions addressed in the discussion group are:

- What mathematics has been uncovered by examining indigenous practices and activities of Micronesian peoples?

- How can this mathematics and the associated practices be used to teach mathematics to indigenous children?

Organziers Chair: A.J. (Sandy) Dawson (USA); Team Members: Danilo Mamangon (USA), Epi Moses (USA), Rhoda Velasquez (USA); Liaison IPC Member: Bill Barton (New Zealand).

\footnotetext{
A.J. (Sandy) Dawson ( $\bowtie)$

University of Hawaii-Mãnoa, Honolulu, USA

(C) The Author(s) 2015

S.J. Cho (ed.), The Proceedings of the 12th International Congress

on Mathematical Education, DOI 10.1007/978-3-319-12688-3_77
} 
- What are the challenges to conducting such research particularly working with elders and dealing with what, at times, is seen as 'protected' knowledge, and developing approaches to the teaching of mathematics with the focused populations?

- What lessons can be learned from this work with indigenous populations?

\section{Structure of Sessions}

\section{Session One: $1.5 \mathrm{~h}$}

- 10 min: introductions and setting the scene

- 50 min: discussion of findings of the mathematics found in Micronesian cultural practices

- 25 min: discussion of pedagogical strategies developed for use with indigenous children

- 5 min: summary of session and closing remarks.

Session Two: $1.5 \mathrm{~h}$

- 5 min: overview of previous day's discussion

- 15 min: further discussion of the pedagogical strategies

- 40 min: small group discussions regarding the challenges of conducting the research and devising implementation strategies

- 20 min: large group discussion and consolidation of the major issues, challenge and observations made during the discussion group-lessons learnt, honouring indigenous knowledge and ways of knowing

- 10 min: closing summary and suggestions for furthering the conversation begun here.

\section{Project MACIMISE}

Project MACIMISE (Mathematics and Culture in Micronesia: Integrating Societal Experiences) is supported by a National Science Foundation grant (0918309). This material in this paper is based on work supported by that grant. The content does not necessarily reflect the views of the NSF or any other agency of the US government. The Project is a collaborative effort between Pacific Resources for Education and Learning (PREL) and the University of Hawaii-Mānoa (UHM) with PREL as the lead organization.

Open Access This chapter is distributed under the terms of the Creative Commons Attribution Noncommercial License, which permits any noncommercial use, distribution, and reproduction in any medium, provided the original author(s) and source are credited. 